
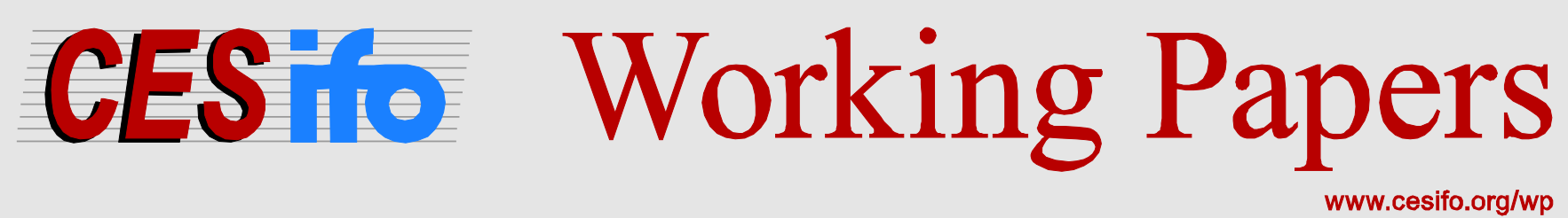

\title{
Human Capital, Social Mobility and the Skill Premium
}

\author{
Konstantinos Angelopoulos \\ James Malley \\ Apostolis Philippopoulos
}

\author{
CESIFO WORKING PAPER NO. 4388 \\ CATEgory 6: Fiscal Policy, Macroeconomics and Growth \\ SEPTEMBER 2013
}

An electronic version of the paper may be downloaded

- from the SSRN website:

- from the RePEc website:

- from the CESifo website:

WWW.SSRN.com

www.RePEc.org

www.CESifo-group.org/wp

\section{CESifo}




\title{
Human Capital, Social Mobility and the Skill Premium
}

\begin{abstract}
This paper develops a dynamic general equilibrium model to highlight the role of human capital accumulation of agents differentiated by skill type in the joint determination of social mobility and the skill premium. We first show that our model captures the empirical comovement of the skill premium, the relative supply of skilled to unskilled workers and aggregate output in the U.S. data from 1970-2000. We next show that endogenous social mobility and human capital accumulation are key channels through which the effects of capital tax cuts and increases in public spending on both pre- and post-college education are transmitted. In particular, social mobility creates additional incentives for the agents which enhance the beneficial effects of policy reforms. Moreover, the dynamics of human capital accumulation imply that, post reform, the skill premium is higher in the short-to medium-run than in the long-run.
\end{abstract}

JEL-Code: E620, J310, J620.

Keywords: social mobility, skill premium, tax and education policy.

\author{
Konstantinos Angelopoulos \\ Department of Economics \\ University of Glasgow \\ G12 8RT Glasgow / United Kingdom \\ konstantinos.angelopoulos@glasgow.ac.uk
}

\author{
James Malley \\ Department of Economics \\ University of Glasgow \\ G12 8RT Glasgow / United Kingdom \\ jim.malley@glasgow.ac.uk
}

\author{
Apostolis Philippopoulos \\ Department of International \& European Economic Studies \\ Athens University of Economics \& Business \\ 10434 Athens / Greece \\ aphil@aueb.gr
}

September 4, 2013

We would like to thank Richard Agènor, Stefan Bühler, Guido Cozzi, Wei Jiang, Jochen Mankart, Kyriakos Neanidis, Tatiana Kirsanova, Ulrich Woitek and seminar participants at the Universities of Manchester, Zürich and St. Gallen for helpful comments and suggestions. We are also grateful for financial support from the ESRC, Grant No. RES-062-23-2292, but the views expressed here are entirely our own. 


\section{Introduction}

There is now an extensive literature on the division of the labour force between college and high school graduates and the resulting wage premium to skilled workers (see e.g. Acemoglu and Autor (2011) and Hornstein et al. (2005) for reviews). The main drivers of the skill/wage premium are widely accepted to be skill biased technical change (SBTC), which raises the demand for skilled labour, and the relative supply of skilled versus unskilled labour (see e.g. Katz and Murphy (1992)). Studies which attribute SBTC to investment-specific technological progress have been shown to match the dynamic behaviour of the skill premium in the data for the U.S. (see e.g. Krusell et al. (2000) and He (2012)).

There is also a comprehensive literature which has examined the occupational choice of economic agents, usually focusing on the distinction between entrepreneurs and workers, and its implications for social mobility (see e.g. Matsuyama (2006) and the literature reviewed therein). A small strand of this literature has studied the occupational choices of skilled and unskilled workers, thus endogenising the relative skill supply in setups that may allow for SBTC and the skill premium paid to college-educated workers (see e.g. Galor and Moav (2000), Maoz and Moav (2004) and He (2012)). In this literature, an unskilled worker can choose to pay a cost when young to become skilled, so that he/she can reap the benefits of the higher (skilled) wage later in life.

The literature has also suggested that economic policy has an impact on the skill premium through its affect on: (i) research and development and thus SBTC (see e.g. Cozzi and Impullitti (2010)); (ii) capital accumulation via tax reforms (see e.g. He and Liu (2008) and Angelopoulos et al. (2013a)); and (iii) labour markets via regulatory intervention (see e.g. Card and Di Nardo (2002)). However, although education policies (see e.g. Galor and Moav (2006) and Galor et al. (2009)) and tax policies (see e.g. Benabou and Ok (2001) and Piketty (1995)) have been considered as important determinants of social mobility, their impact on the joint determination of social mobility and the skill premium has generally not been studied. ${ }^{1}$

This paper first extends the literature concentrating on the endogenous joint determination of social mobility and the skill premium by treating the former as a dynamic process depending on the human capital accumulation decisions of agents differentiated by skill type. In particular, we develop

\footnotetext{
${ }^{1}$ An exception is the work by $\mathrm{He}$ and Liu (2008), who consider a representative agent that allocates his/her time to working in the skilled and unskilled sectors, as well as to creating the skill required for skilled employment, and examines the effects of taxation and education subsidies on the skill premium and the supply of skill.
} 
and incorporate a micro-founded model of work and education choices into an infinite-horizon dynamic general equilibrium (DGE) model to facilitate the study of the effects of policy. This then allows us to contribute to the policy literature through the evaluation of the dynamic effects of tax reforms and education policies on economic outcomes, with a particular emphasis on social and wage inequality (measured by the percentage of skilled labour in the population and the skilled premium respectively). ${ }^{2}$

To achieve our aims, we model a representative dynasty which is comprised of two types of members that supply either skilled or unskilled labour services. Both types can accumulate human capital to increase their labour productivity, as either skilled or unskilled workers, by investing part of their time into creating new human capital (as in e.g. Lucas (1988) and Tamura (1991)). However, the human capital accumulated by the unskilled also contributes to equipping them with the knowledge to become skilled workers and thus to improving their position on the social ladder. In particular, the switch to the skilled type is achieved once a threshold for the level of skill is reached. Human capital accumulation also depends on government education spending, in addition to workers' efforts, so that social mobility depends on both individual choices and policy outcomes. We also allow for the possibility that the threshold of skill required to find employment in the skilled sector depends on the level of human capital of skilled workers. We assume that this is an unintentional effect of the increase in human capital required in skilled jobs and we model it as an externality that the representative household does not internalize when making its choices. ${ }^{3}$

Following the literature, to capture SBTC, we use a constant elasticity of substitution (CES) production function which allows capital to complement skilled labour more than unskilled (see e.g. Krusell et al. (2000)). In this framework, an increase in the effective relative supply of skilled labour, brought about by an increase in social mobility and/or an increase in the relative human capital of skilled, will tend to decrease the skill premium. In contrast, an increase in the physical capital stock will be skill-biased and thus contribute to an increase in the skill premium. However, an increase in the skill premium and, more generally, in the returns to the skilled status

\footnotetext{
${ }^{2}$ Issues relating to social mobility are generally tackled in the literature using overlapping generations models. Our approach allows us to concentrate on an annual frequency to analyse the dynamic effects of policy on the transition path as well as on the long run.

${ }^{3}$ While externalities in higher education have been considered in the literature on growth and inequality (see e.g. Penalosa and Wälde (2000) and Eicher and Penalosa (2002)), we are not aware of studies that have examined the importance of externalities arising from labour augmenting human capital accumulation activities of skilled labour on the effort of unskilled to become skilled.
} 
(defined to include access to both skilled employment and skilled education), creates an incentive for more effort to climb the social ladder. Therefore, policies that affect the skill premium will also have an indirect effect on social mobility through the human capital accumulation required to become skilled. Also, policies that affect human capital and social mobility will have an indirect effect on the skill premium, via the relative skill supply channel.

The tax policy menu we consider includes levies on capital and labour income. These are used to generate revenue to finance two types of government education spending that augment human capital accumulation of unskilled and skilled members, as well as other government spending on goods and services. We are particularly interested in distinguishing education policies that affect the human capital accumulation of unskilled labour (typically associated with school level and undergraduate public education spending) from policies that affect the human capital accumulation of skilled labour (usually in the form of support of postgraduate education, further training for professionals and other skilled workers and research grants).

We find that the model with endogenous social mobility can capture the empirical co-movements of the skill premium, the relative supply of skilled to unskilled workers and aggregate output in the U.S. data from 1970-2000. In particular, we find that the model predictions for these empirical comovements are improved when we allow for positive externalities from skilled human capital on social mobility. Our policy results first show that endogenous social mobility creates additional incentives for the agents which enhance the beneficial effects of policy on aggregate outcomes and wage equality. Second, that important dynamic effects of policy on the skill premium are captured by allowing human capital accumulation to affect social mobility. In particular, post reform, the skill premium is higher in the short- to medium-run than in the long-run. Third, that although all policy reforms considered here lead to an increase in output and social mobility, their implications regarding the skill premium differ. In particular, the skill premium increases after a capital tax cut and decreases after an increase in spending on education for unskilled agents and in spending on education for skilled agents. $^{4}$

The rest of this paper is organised as follows. Section 2 sets out the theoretical model. Sections 3 discusses the calibration and model evaluation. Section 4 presents the policy analysis and Section 5 concludes.

\footnotetext{
${ }^{4}$ Regarding all three results above, the effects of public spending on education for skilled agents are dependent on the externality that skilled human capital has on social mobility. In particular, a negative externality generally reduces many of the positive effects of this policy reform.
} 


\section{The model}

In this section, we develop a model with a division of labour that allows for endogenous labour augmenting technology through the accumulation of human capital and social mobility in the form of an endogenous skill supply. In particular, we use a closed-economy setup where a representative household is an infinitely-lived dynasty with both skilled and unskilled members. ${ }^{5}$ These members differ in the type of labour services they offer and also in the type of human capital they create. Following the literature, the human capital of each type of worker can accumulate over time thanks to individual time devoted to education and public education spending. Social mobility is incorporated by allowing unskilled members to switch to skilled status once their stock of human capital reaches a threshold level.

The firms use capital, skilled labour and unskilled labour to produce a homogeneous product. Since skilled labour is more complementary to capital than unskilled labour, capital accumulation, as well as technological developments and policies that are capital augmenting, favor the skilled wage premium as in e.g. Krusell et al. (2000) and Hornstein et al. (2005). In contrast, increases in the relative supply of skilled labour tend to reduce the skill premium. Finally, the government uses capital and labour taxes to finance spending on two types of public education services and spending on other goods and services.

\subsection{Human capital and social mobility}

The numbers of skilled and unskilled members at time $t$ for the representative household are denoted as $N_{t}^{s}$ and $N_{t}^{u}$ respectively. Thus, the total size of the household (population) is $N_{t}=N_{t}^{s}+N_{t}^{u}{ }^{6}$ The respective population shares are defined as $n_{t}^{s}=N_{t}^{s} / N_{t}$ and $n_{t}^{u}=N_{t}^{u} / N_{t}$, where $N_{t}$ is assumed to grow at an exogenous net rate, $\theta=\frac{N_{t+1}}{N_{t}}-1$, to allow new unskilled members to join the household.

Each household member, $i=s, u$, accumulates knowledge in the form of

\footnotetext{
${ }^{5}$ The modelling assumption that the population is made up by a representative household that is composed of members that differ in their labour market position is a standard modelling device in dynamic macroeconomic models with two-state heterogeneity in the labour market. Examples include the models incorporating search and matching labour market frictions and unemployment (see e.g. Rogerson and Shimer (2011) and Arseneau and Chugh (2012)). We adapt this modelling device here to capture a two-state heterogeneity in the labour market consisting of skilled and unskilled workers.

${ }^{6}$ The total size of the population, $N_{t}$, is assumed to be large. This allows us to approximate the distribution of abilities in skill acquisition by a continuous function below.
} 
human capital:

$$
h_{t+1}^{i}=\left(1-\delta^{h}\right) h_{t}^{i}+\left(g_{t}^{i}\right)^{\gamma}\left(e_{t}^{i}\right)^{1-\gamma}
$$

where $0<\delta^{h}<1$ is the human capital depreciation rate; $e_{t}^{i}$ is time devoted to education; $g_{t}^{i}$ is per member public education spending; and $0<\gamma<1$ is a fixed productivity parameter. For skilled members, knowledge acquisition through post-college and vocational training, job-related training seminars, etc., is productivity enhancing. For unskilled members, in addition to its productivity augmenting role, human capital accumulation via primary, secondary and college education also increases unskilled labour's potential for becoming skilled.

In our setup, when the effective skill level of an unskilled individual, defined as $S_{t}^{u}$, is higher than an exogenous level, $S^{*}$, he/she becomes skilled. We assume that $S_{t}^{u}$ is the outcome of a combination of endogenous human capital or knowledge, $h_{t}^{u}$, with exogenous factors that are specific to each individual, $\phi_{t}$. The latter captures idiosyncratic abilities, due to e.g. individual differences in aspirations, neighborhood environment, school quality, health, etc. ${ }^{7}$

We also allow for the possibility that $S_{t}^{u}$ depends on the average level of skilled workers' human capital, $\bar{h}_{t}^{s}$. This captures the idea that as the skilled workers accumulate more knowledge, it may become more difficult or easier, ceteris paribus, for the unskilled to find employment in skilled jobs. The potentially negative effect arises since, as skilled workers accumulate more knowledge, they raise the skill threshold and make it more difficult for the unskilled to become skilled. In this case, more individual unskilled effort is required to become skilled. In contrast, increasing knowledge levels for the skilled might create positive spillover effects and increase the effectiveness of individual investment in school level and college education. Irrespective of the direction of effects on the efforts of the unskilled, we assume that this is an unintentional effect of the increase in human capital needed in skilled jobs and we model it as an externality that the representative household does not internalise when making its choices.

These relationships can be defined more formally as follows.

Definition 1. an unskilled worker becomes skilled if:

$$
S_{t}^{u} \equiv \phi_{t} h_{t}^{u}\left(\bar{h}_{t}^{s}\right)^{-\psi}>S^{*}
$$

\footnotetext{
${ }^{7}$ This idiosyncratic term generates a type of ex ante heterogeneity within the class of unskilled labour, without which the proportion of unskilled members that become skilled in each period would be either zero or one (see also e.g. Heckman et al. (1998) and He (2012) for similar "idiosyncratic disutility costs").
} 
where $\phi_{t}$ is distributed exponentially across the population and independently in each time period, with a probability density function (pdf), $f_{\phi} ; S^{*}>0$ denotes the skill threshold; and $-\infty<\psi<\infty$ allows us to capture the extent of the positive or negative externality. The pdf for $\phi$ is given by:

$$
f_{\phi}=\zeta e^{(-\zeta \phi)}, \phi>0
$$

where $1 / \zeta$ is the mean of $f_{\phi}$.

The condition defined in (2) can be rewritten as:

$$
\phi_{t}>S^{*}\left(\bar{h}_{t}^{s}\right)^{\psi}\left(h_{t}^{u}\right)^{-1} \equiv \phi_{t}^{*}
$$

which suggests that an increase in the human capital of unskilled agents lowers the critical level of idiosyncratic abilities required for becoming skilled, $\phi_{t}^{*} .8$

At the beginning of each period, the unskilled agents observe their $\phi_{t}$ shock and, given (4), they know whether they can find employment as skilled or unskilled. If they become skilled, we assume that the newly skilled members share the same initial conditions with existing skilled members at period $t .^{9}$ If they remain unskilled, namely if $\phi_{t} h_{t}^{u}\left(\bar{h}_{t}^{s}\right)^{-\psi} \leq S^{*}$, the household may decide to further invest in education so as to increase the share of members becoming skilled in the next time period..$^{10}$

Equation (4) implies that the proportion of unskilled household members who become skilled, $\pi^{u}$, is given by:

$$
\pi^{u}=1-\int_{0}^{\phi^{*}} f_{\phi} d \phi .
$$

\footnotetext{
${ }^{8}$ Since we focus on between-group wage inequality and not on within-group labour income inequality, we consider the case where all unskilled members are identical in each time period before the realisation of the idiosyncratic ability shock is known. This requires that new household members share a common value of human capital with existing unskilled members at the period $t$ when they join the household.

${ }^{9}$ This follows from the previous assumption on equality regarding initial conditions within the class of unskilled, and allows us to focus on between-group, as opposed to withingroup differences. See also e.g. Curdia and Woodford (2009) for similar assumptions regarding within-group initial conditions.

${ }^{10}$ Note that there is no need for unskilled members to insure themselves from unfavourable $\phi_{t}$ shocks, as this type of insurance is provided by the household. This is also a common assumption in two-state unemployment models with search and matching (see e.g. Rogerson and Shimer (2011) and Arseneau and Chugh (2012)) and is discussed in more detail in our context in the next sub-section.
} 
Evaluating the definite integral of (5) gives the social mobility function:

$$
\pi^{u}=1-F_{\phi}\left[\phi^{*}\left(h^{u}, \bar{h}^{s} ; S^{*}, \psi\right)\right]
$$

where, $F_{\phi}=1-e^{(-\zeta \phi)}$ is the cumulative distribution function (cdf) of $\phi$. Note that the exponential distribution assigns a decreasing probability to higher outcomes of $\phi$. Thus, the marginal effect of $h^{u}$ on $\pi^{u}$ is positive and increasing, reflecting increasing returns to education.

Given (6), the numbers of skilled and unskilled members change over time as follows:

$$
N_{t+1}^{s}=N_{t}^{s}+\pi_{t+1}^{u} N_{t}^{u}
$$

and

$$
N_{t+1}^{u}=N_{t}^{u}+\theta N_{t}-\pi_{t+1}^{u} N_{t}^{u}
$$

where,

$$
\pi_{t+1}^{u}=e^{\left(-\zeta S^{*}\left(\bar{h}_{t+1}^{s}\right)^{\psi}\left(h_{t+1}^{u}\right)^{-1}\right)} .
$$

Equivalently, the population shares of skilled and unskilled members are given by: ${ }^{11}$

$$
n_{t+1}^{s}=\frac{n_{t}^{s}+\pi_{t+1}^{u} n_{t}^{u}}{1+\theta}
$$

and

$$
n_{t+1}^{u}=\frac{n_{t}^{u}+\theta-\pi_{t+1}^{u} n_{t}^{u}}{1+\theta}
$$

where $n_{t+1}^{s}+n_{t+1}^{u}=1 .{ }^{12}$

\subsection{The problem of the household}

In this setup, the head of the household makes all the choices on behalf of its members, i.e. it chooses consumption and investment, and also work and education-time, for each type of member by maximising the aggregate welfare of all its members. Implicitly, the household provides insurance to all its members by guaranteeing them the same level of consumption and welfare.

\footnotetext{
${ }^{11}$ The evolution of the share of skilled (10), has, in fact, analogies with the basic employment evolution equation in search and matching models (see e.g. equation (7) in Rogerson and Shimer (2011)). In our case, the social mobility function, $\pi_{t}^{u}$, plays a role similar to the job finding probability in the search literature.

${ }^{12}$ As long as $0<\pi^{u}<1$, and $\theta>0$ equation (10) implies a well defined steady-state, where the share of skilled converges to a stationary quantity, given by $n^{s}=\pi^{u} /\left(\pi^{u}+\theta\right)$, where $0<n^{s}<1$.
} 
Formally, the household maximises the discounted lifetime utility of its members:

$$
\sum_{t=0}^{\infty} \beta^{t} u\left(c_{t}\right)
$$

where $c_{t} \equiv\left(c_{t}^{s}\right)^{n_{t}^{s}}\left(c_{t}^{u}\right)^{n_{t}^{u}}$ is a weighted average of skilled and unskilled members' consumption; and $0<\beta<1$ is the time preference rate. ${ }^{13}$ The period utility function, $u(\cdot)$, is increasing and strictly concave. The form we employ for the period utility function is:

$$
u\left(c_{t}\right)=\frac{c_{t}^{1-\sigma}}{1-\sigma}
$$

where $\sigma>0$ is the coefficient of relative risk aversion.

The household's budget constraint is:

$$
n_{t}^{s} c_{t}^{s}+n_{t}^{u} c_{t}^{u}+i_{t}=\left(1-\tau_{t}^{l}\right)\left(n_{t}^{s} w_{t}^{s} h_{t}^{s} l_{t}^{s}+n_{t}^{u} w_{t}^{u} h_{t}^{u} l_{t}^{u}\right)+\left(1-\tau_{t}^{k}\right) r_{t} k_{t}
$$

where $i_{t}$ is investment in physical capital; $w_{t}^{s}$ and $w_{t}^{u}$ are the returns to skilled labour and unskilled labour respectively; $h_{t}^{s} l_{t}^{s}$ and $h_{t}^{u} l_{t}^{u}$ are the effective supply of skilled and unskilled labour; $r_{t}$ is the return to physical capital; and $\tau_{t}^{l}$ and $\tau_{t}^{k}$ are the tax rates on labour and capital income.

The motion of physical capital is given by:

$$
k_{t+1}=\left(1-\delta^{k}\right) k_{t}+i_{t}
$$

where $0<\delta^{k}<1$ is the physical capital depreciation rate.

Each type of worker, $i=s, u$, allocates one unit of his/her effort time to work and education:

$$
l_{t}^{i}+e_{t}^{i}=1 .
$$

Note that (1) and (16) differ for skilled and unskilled members, implying that skilled and unskilled workers are distinct in the labour market and the education sectors, consistent with the literature on social mobility.

The household, taking prices and policy as given, chooses the time paths of $c_{t}^{s}, c_{t}^{u}, i_{t}, k_{t+1}, l_{t}^{s}, l_{t}^{u}, e_{t}^{s}, e_{t}^{u}, h_{t+1}^{s}, h_{t+1}^{u}$, and $n_{t+1}^{s}$ to maximize (12) and (13) subject to constraints (1), (10), (14) - (16).

\footnotetext{
${ }^{13}$ Note that at the household level, there is no uncertainty regarding the proportion of agents who become skilled. Also, for simplicity, there is no uncertainty regarding the technological processes (see the discussion of the firm problem below). There is, of course, uncertainty, for each individual within the class of unskilled workers, regarding their progression to skilled employment. However, as discussed earlier, we assume that the representative household provides complete income insurance to its members. In particular, the functional form that aggregates individual consumption in the utility function implies that the household finds it optimal to equate the consumption levels for the two types of agents. This is similar to e.g. the assumption that labour unions provide income insurance to their members (see e.g. Pissarides (1998) and Ardagna (2007)).
} 


\subsubsection{Trade-offs relating to human capital and social mobility}

We now study some basic trade-offs in the household's behavior. This will help us to understand the quantitative results below. The Euler-equation for skilled human capital illustrates the trade-off associated with choosing $h_{t+1}^{s}$ :

$$
\lambda_{t}^{H S}=\beta\left[\lambda_{t+1}^{B C}\left(1-\tau_{t+1}^{l}\right) \Omega_{1}+\lambda_{t+1}^{H S}\left(1-\delta^{s}\right)\right]
$$

where $\Omega_{1} \equiv n_{t+1}^{s} w_{t+1}^{s} l_{t+1}^{s}$ and $\lambda_{t+1}^{B C}$ and $\lambda_{t+1}^{H S}$ are the Lagrange multipliers attached to the budget constraint and the skilled human capital equation respectively. The representative household equates the opportunity cost of education-time to produce an extra unit of human capital valued in utility terms, $\lambda_{t}^{H S}$, to the benefits, given by the discounted future increase in net labour income and human capital, valued respectively by $\lambda_{t+1}^{B C}$ and $\lambda_{t+1}^{H S}$.

The choice of the quantity of unskilled human capital, $h_{t+1}^{u}$, includes the same costs and benefits as above, but the benefits in this case also include the increase in the share of household members who become skilled due to a marginal increase in $h_{t+1}^{u}$ :

$$
\lambda_{t}^{H U}=\beta\left(\lambda_{t+1}^{B C}\left(1-\tau_{t+1}^{l}\right) \Omega_{2}+\lambda_{t+1}^{H U}\left(1-\delta^{u}\right)\right)+\lambda_{t}^{S S} \frac{\left(1-n_{t+1}^{s}\right)}{(1+\theta)} \frac{\partial \pi_{t+1}^{u}}{\partial h_{t+1}^{u}}
$$

where $\Omega_{2} \equiv\left(1-n_{t+1}^{s}\right) w_{t+1}^{u} l_{t+1}^{u}, \lambda_{t}^{H U}$ is the multiplier attached to the unskilled human capital equation; $\lambda_{t}^{S S}$ is the multiplier associated with the equation for the skilled employment share; and $\frac{\partial \pi_{t+1}^{u}}{\partial h_{t+1}^{u}} \equiv \frac{S^{*}\left(h_{t+1}^{s}\right)^{\psi} \zeta e^{\left(\frac{-\zeta S^{*}\left(\bar{h}_{t+1}^{s}\right)^{\psi}}{h_{t+1}^{u}}\right)}}{\left(h_{t+1}^{u}\right)^{2}}$.

The Euler-equation for the share of skilled labour illustrates the trade-off associated with choosing $n_{t+1}^{s}$ :

$$
\lambda_{t}^{S S}=\beta \lambda_{t+1}^{B C}\left(1-\tau_{t+1}^{l}\right)\left(\Omega_{3}-\Omega_{4}\right)+\left(\frac{\beta}{1+\theta}\right) \lambda_{t+1}^{S S}\left(1-e^{\left(\frac{-\zeta S^{*}\left(\bar{h}_{t+2}^{s}\right)^{\psi}}{h_{t+2}^{u}}\right)}\right)
$$

where $\Omega_{3} \equiv w_{t+1}^{s} h_{t+1}^{s} l_{t+1}^{s}$ and $\Omega_{4} \equiv w_{t+1}^{u} h_{t+1}^{u} l_{t+1}^{u}$. Here the costs of foregone unskilled work-time required to increase the share of members that find employment in skilled jobs, evaluated in utility terms via $\lambda_{t}^{S S}$, is equal to, in equilibrium, the benefits from increasing $n_{t+1}^{s}$. The latter are given by the discounted future increase in net labour income of being employed in skilled versus unskilled jobs, valued in utility terms by $\lambda_{t+1}^{B C}$. The benefits are further augmented by the fact that a higher share of skilled increases the future stock of skilled, and this is valued in utility terms by $\lambda_{t+1}^{S S}$. 
Note that by comparing $\Omega_{3}$ to $\Omega_{4}$ in the above condition for the share of skilled labour, we can see that an increase in the skill premium will increase the benefits of employment in the skilled sector and is thus expected to increase social mobility. Moreover, it is useful to note that the increase in the human capital of skilled, relative to unskilled labour, also increases future benefits from employment in the skilled sector and is thus also expected to increase social mobility.

\subsection{The firm}

There are $N_{t}^{f}$ identical firms at each $t$. For simplicity, we assume $N_{t+1}^{f}=$ $(1+\theta) N_{t}$, which implies that the number of firms equals the number of household members. Each firm produces output, $y_{t}^{f}$, using physical capital, $k_{t}^{f}$, and the two distinct types of labour, unskilled, $l_{t}^{u, f}$, and skilled, $l_{t}^{s, f}$, where the latter is relatively more complementary to capital than unskilled labour. The production function is given by a constant returns to scale (CRS) technology assumed to take a constant elasticity of substitution (CES) specification following e.g. Krusell et al. (2000) and He (2012):

$$
y_{t}^{f}=A\left\{\mu\left(l_{t}^{u, f}\right)^{\alpha}+(1-\mu)\left[\rho\left(B k_{t}^{f}\right)^{\nu}+(1-\rho)\left(l_{t}^{s, f}\right)^{\nu}\right]^{\frac{\alpha}{\nu}}\right\}^{\frac{1}{\alpha}}
$$

where $A$ is the level of total factor productivity; $B$ is the level of capital productivity; $\alpha, \nu<1$, are the parameters determining the factor elasticities, i.e. $1 /(1-\alpha)$ is the elasticity of substitution between capital and unskilled labour and between skilled and unskilled labour, whereas $1 /(1-\nu)$ is the elasticity of substitution between capital and skilled labour; and $0<\mu, \rho<1$ are the factor share parameters. The above CES form allows us to capture the capital-skill complementarity, which is considered to be one of the main drivers of the skill premium and wage inequality (see e.g. Krusell et al. (2000) and Hornstein et al. (2005)).

Each firm acts competitively by choosing inputs, $k_{t}^{f}, l_{t}^{s, f}$ and $l_{t}^{u, f}$, to maximise profits:

$$
\Pi_{t}^{f} \equiv y_{t}^{f}-r_{t} k_{t}^{f}-w_{t}^{s} l_{t}^{s, f}-w_{t}^{u} l_{t}^{u, f}
$$

subject to the technology constraint, (19). In equilibrium, profits, $\Pi_{t}^{f}$, are zero.

Notice that the different roles played by skilled and unskilled labour in the production function imply that there will be a skill premium for the former, in the sense that the ratio of $w_{t}^{s}$ to $w_{t}^{u}$ will be larger than unity. 


\subsection{Government budget constraint}

The government taxes capital and labour income to finance the two types of public education spending and general-purpose public consumption. Note that the latter is used for calibration purposes only. Thus, the within period budget constraint of the government is simply:

$$
g_{t}^{u}+g_{t}^{s}+g_{t}^{c}=\tau_{t}^{k} r_{t} k_{t}+\tau_{t}^{l}\left(n_{t}^{s} w_{t}^{s} h_{t}^{s} l_{t}^{s}+n_{t}^{u} w_{t}^{u} h_{t}^{u} l_{t}^{u}\right)
$$

where $g_{t}^{c}$ denotes public consumption.

\subsection{Market-clearing conditions}

The market-clearing conditions for capital, skilled labour, unskilled labour and goods are respectively:

$$
\begin{gathered}
k_{t}^{f}=k_{t} \\
l_{t}^{s, f}=n_{t}^{s} l_{t}^{s} h_{t}^{s} \\
l_{t}^{u, f}=n_{t}^{u} l_{t}^{u} h_{t}^{u} \\
y_{t}^{f}=c_{t}+k_{t+1}-(1-\delta) k_{t}+g_{t}^{u}+g_{t}^{s}+g_{t}^{c}
\end{gathered}
$$

where (25) also gives the resource constraint of the economy.

\subsection{Decentralized competitive equilibrium}

The dynamics of the economy are characterized by the first-order conditions of the representative household and firms, the government budget constraint, the aggregate resource constraint and government policies. ${ }^{14} \mathrm{~A}$ symmetric decentralized competitive equilibrium (DCE) can be defined as follows.

Definition 2. A symmetric DCE is an allocation sequence $\left\{c_{t}^{s}, c_{t}^{u}, i_{t}, k_{t+1}, l_{t}^{s}\right.$, $\left.l_{t}^{u}, e_{t}^{s}, e_{t}^{u}, h_{t+1}^{s}, h_{t+1}^{u}, n_{t}^{s}\right\}_{t=0}^{\infty}$, a price sequence $\left\{w_{t}^{s}, w_{t}^{u}, r_{t}\right\}_{t=0}^{\infty}$, a sequence of policy instruments $\left\{\tau_{t}^{k}, \tau_{t}^{l}, g_{t}^{u}, g_{t}^{s}, g_{t}^{c}\right\}_{t=0}^{\infty}$ and initial conditions for $k_{0}, h_{0}^{s}, h_{0}^{u}$, and $n_{0}^{s}$ such that:

1. the representative household and firms undertake their respective optimization problems;

2. all budget constraints are satisfied; and

3. all markets clear.

\footnotetext{
${ }^{14}$ To preserve space all these conditions are not reported here but are available on request.
} 
We discuss below the computational methods implemented to solve for the dynamic equilibrium paths. The stability properties of the equilibrium are discussed in Appendix A.

\subsection{The skill premium}

We can now examine the factors that drive the skill premium in our setup. The competitive equilibrium above implies that the skill premium is given by:

$$
\frac{w_{t}^{s}}{w_{t}^{u}}=\frac{(1-\mu)}{\mu}(1-\rho)\left(\Omega_{5}\right)^{\nu-1}\left(\Omega_{6}\right)^{1-\alpha}\left[\rho\left(B k_{t}\right)^{\nu}+(1-\rho)\left(\Omega_{5}\right)^{\nu}\right]^{\frac{\alpha}{\nu}-1}
$$

where $\Omega_{5} \equiv n_{t}^{s} h_{t}^{s} l_{t}^{s}$ and $\Omega_{6} \equiv\left(1-n_{t}^{s}\right) h_{t}^{u} l_{t}^{u}$. Consistent with the literature (see e.g. Krusell et al. (2000) and He and Liu (2008)), the skill premium is, ceteris paribus, increasing in the capital stock, as long as $\alpha>\nu$ and $0<\mu, \rho, \alpha<1$. To see this, note that:

$$
\begin{aligned}
\frac{\partial\left(\frac{w_{t}^{s}}{w_{t}^{u}}\right)}{\partial k_{t}} & =\frac{(1-\mu)}{\mu}(1-\rho)\left(\Omega_{5}\right)^{\nu-1}\left(\Omega_{6}\right)^{1-\alpha} \times \\
& \times\left[\rho\left(B k_{t}\right)^{\nu}+(1-\rho)\left(\Omega_{5}\right)^{\nu}\right]^{\frac{\alpha}{\nu}-2}(\alpha-\nu) \rho B\left(B k_{t}\right)^{\nu-1} .
\end{aligned}
$$

Moreover, note that the effective relative skill supply in this model is given by $\frac{n_{t}^{s} h_{t}^{s} l_{t}^{s}}{\left(1-n_{t}^{s}\right) h_{t}^{u} t_{t}^{u}}$. In models that exclude human capital and social mobility the relative skill supply is defined as $\frac{l_{t}^{s}}{l_{t}^{u}}$. Hence, in our model, human capital of each type of agent augments their effective labour supply and thus tends, ceteris paribus, to increase the skill premium, for the case of unskilled human capital, and decrease it, for the case of skilled human capital. To see this, note that:

$$
\begin{gathered}
\frac{\partial\left(\frac{w_{t}^{s}}{w_{t}^{u}}\right)}{\partial\left(\left(1-n_{t}^{s}\right) h_{t}^{u} l_{t}^{u}\right)}=\frac{(1-\mu)}{\mu}(1-\rho)(1-\alpha)\left(\Omega_{5}\right)^{\nu-1}\left(\Omega_{6}\right)^{-\alpha} \times \\
\times\left[\rho\left(B k_{t}\right)^{\nu}+(1-\rho)\left(\Omega_{5}\right)^{\nu}\right]^{\frac{\alpha}{\nu}-1}
\end{gathered}
$$

and

$$
\begin{aligned}
\frac{\partial\left(\frac{w_{t}^{s}}{w_{t}^{u}}\right)}{\partial\left(n_{t}^{s} h_{t}^{s} l_{t}^{s}\right)} & =\frac{(1-\mu)}{\mu}(1-\rho)(\nu-1)\left(\Omega_{5}\right)^{\nu-2}\left(\Omega_{6}\right)^{1-\alpha} \times \\
& \times\left[\rho\left(B k_{t}\right)^{\nu}+(1-\rho)\left(\Omega_{5}\right)^{\nu}\right]^{\frac{\alpha}{\nu}-1}+\frac{(1-\mu)}{\mu}(1-\rho)\left(\Omega_{5}\right)^{\nu-1} \times \\
& \times\left(\Omega_{6}\right)^{1-\alpha}\left[\rho\left(B k_{t}\right)^{\nu}+(1-\rho)\left(\Omega_{5}\right)^{\nu}\right]^{\frac{\alpha}{\nu}-2}(\alpha-\nu)(1-\rho) \nu\left(\Omega_{5}\right)^{\nu-1} .
\end{aligned}
$$


The above expressions can be signed as positive and negative respectively since all quantities are positive and $\nu<0$ and $0<\mu, \rho, \alpha<1$.

Regarding the effect of social mobility, it can be shown that in our model, the skill premium is, ceteris paribus, decreasing in the share of skilled labour, for values of $\nu<0$ and $0<\mu, \rho, \alpha<1$. To see this, note that:

$$
\frac{\partial\left(\frac{w_{t}^{s}}{w_{t}^{u}}\right)}{\partial n_{t}^{s}}=\frac{(1-\mu)(1-\rho) h_{t}^{u} l_{t}^{u}\left(\Omega_{5}\right)^{\nu}\left((1-\rho)\left(\Omega_{5}\right)^{\nu}+\rho\left(B k_{t}\right)^{\nu}\right)^{\frac{\alpha}{\nu}-2} \Omega_{7}}{\mu\left(n_{t}^{s}\right)^{2} h_{t}^{s} l_{t}^{s}\left(\Omega_{6}\right)^{\alpha}}
$$

where $\Omega_{7} \equiv[(\rho-1)(1-\alpha)]\left(\Omega_{5}\right)^{\nu}+\left[\nu\left(1-n_{t}^{s}\right)+\alpha n_{t}^{s}-1\right] \rho\left(B k_{t}\right)^{\nu}$. The derivative is negative if $\Omega_{7}<0$. This follows since $\nu<0 \Rightarrow\left[\nu\left(1-n_{t}^{s}\right)+\alpha n_{t}^{s}\right.$ $-1]<0 \Rightarrow \Omega_{7}<0$.

To summarise, as in the literature, the skill premium increases when the capital stock increases and when the relative effective labour supply of skilled decreases. In our model, given that effective labour supply is driven by social mobility and the two types of human capital, the above analysis implies that, all else constant, increases in social mobility and skilled human capital work to lower the skill premium. In contrast, controlling for social mobility, increases in the human capital of the unskilled tends to increase the skill premium.

\section{Quantitative analysis}

In this section we calibrate the model and solve for the steady-state. We examine four versions of the model, three with social mobility (i.e. with no externalities and with both negative and positive externalities in the social mobility function) and one without social mobility. In the latter case, the shares of skilled and unskilled members in the total population remain fixed as is typically assumed in the skill premium literature.

\subsection{Calibration and long-run solution}

The calibrated parameters for the model presented in Section 2 are shown in Table 1. We use values that are common in the literature and choose the remaining parameters so that the model's steady-state is consistent with the relevant data averages for the U.S. economy over the period $1970-2000 .{ }^{15}$ The relative skill supply and skill premium data are from Acemoglu and Autor (2011). These have been extensively analysed in e.g. Autor et al. (2008)

\footnotetext{
${ }^{15}$ Note that this is the time period used in most econometric and empirical studies on the skill premium that we use to parameterise the elasticities in the production function.
} 
and Acemoglu and Autor (2011). ${ }^{16}$ We also use the ECFIN effective capital and labour tax rates from Martinez-Mongay (2000). ${ }^{17}$ The remaining data relating to GDP and its components are from the U.S. NIPA accounts.

Table 1: Parameter values

\begin{tabular}{lrl}
\hline \hline parameter & value & definition \\
\hline $0<\frac{1}{1-\alpha}<1$ & 1.669 & capital to unskilled labour elasticity \\
$0<\beta<1$ & 0.980 & rate of time preference \\
$0 \leq \delta \leq 1$ & 0.080 & depreciation rate on physical capital \\
$0 \leq \delta^{h} \leq 1$ & 0.100 & depreciation rate on human capital \\
$0 \leq \gamma \leq 1$ & 0.100 & education spending productivity parameter \\
$\frac{1}{1-\nu}>0$ & 0.669 & capital to skilled labour elasticity \\
$0<\rho<1$ & 0.595 & capital weight in composite input share \\
$\sigma>1$ & 2.000 & coefficient of relative risk aversion \\
$\theta>0$ & 0.010 & net population growth rate \\
$0<g^{u} / y<1$ & 0.099 & $g^{u}$ spending share in output \\
$0<g^{s} / y<1$ & 0.010 & $g^{s}$ spending share in output \\
$0<g^{c} / y<1$ & 0.131 & $g^{c}$ spending share in output \\
$0<\tau^{k}<1$ & 0.309 & capital tax rate \\
$0<\tau^{l}<1$ & 0.211 & labour tax rate \\
& & \\
\hline & Parameters for externalities \\
\hline & & $\psi$ \\
& &
\end{tabular}

We use commonly employed values for the rate of time preference, $\beta$, the depreciation rate on physical capital, $\delta$, the coefficient of relative risk aversion $\sigma$, and the population growth rate, $\theta$. We follow Perli and Sakellaris (1998) and calibrate the depreciation rate on human capital, $\delta^{h}$, to be $10 \%$. The

\footnotetext{
${ }^{16}$ Following Autor et al. (2008) and Acemoglu and Autor (2011), the relative skill supply is calculated as the ratio of college equivalent to non-college equivalent labour supply in efficiency units. The skill premium is defined as the ratio of college to high school wages.

${ }^{17}$ In particular, we use the LITR and KITN rates for effective average labour and capital taxes respectively, as they treat self-employed income as capital income in the calculations.
} 
tax rates are set to their data averages. Finally, we normalise the exogenous productivity parameters, i.e. $A, B$, and $S^{*}$, to unity.

Two key steady-state variables we concentrate on matching to the data averages include the skill premium (i.e. 1.648) and the relative skill supply (i.e. 0.876). The elasticities in the production function are parameterised using the estimates in Krusell et al. (2000), i.e. $\nu=-0.495$ and $\alpha=0.401$, implying elasticities of substitution between capital and skilled labour and between capital (or skilled labour) and unskilled labour of about 0.67 and 1.67 respectively. ${ }^{18}$ We then calibrate $\rho$ so that our solution implies that in the steady-state the capital share in income is about a third. The production function parameter $\mu$ is set so that the model predicts a steady-state skill premium that is equal to the average of the 1970-2000 period of $1.648 .{ }^{19}$ The key parameter that affects the share of skilled labour in the labour force is $\zeta$, which determines the mean in the distribution of the idiosyncratic abilities, $\phi_{t}$, in the social mobility function. This is calibrated so that the model's prediction of the share of skilled labour is equal to the data average of the share of skilled workers in the total labour force of about 0.467 which implies a relative skill supply of 0.876 .

We also target average public spending shares of output in the data (see Table 1). Government education spending, $g^{u}, g^{s}$, and the education spending productivity parameter, $\gamma$, are calibrated so that the public education share in GDP and the total government spending in GDP are consistent with the data. In particular, government spending on education for unskilled is calibrated to be ten times higher than that on skilled, reflecting the fact that post-college education spending and spending on activities that may increase the productivity of skilled labour is only a small fraction of government spending on education. Given that government spending on education is about 7\% of GDP in national accounts (see the Bureau of Economic Analysis), we calibrate the government spending on labour augmenting technology for both skilled and unskilled to be about $10 \%$ of output, to capture the potential effects of government spending on human capital outside of formal education (e.g. in the form of training for skilled and unskilled workers in administration, health, defense, government support of R\&D, etc.).

We also examine the importance of externalities in the social mobility function by considering three special cases for $\psi$ : (i) the benchmark case without externalities, obtained by setting $\psi=0$; (ii) negative externalities where $\psi=1$; and (iii) positive externalities where $\psi=-1$. The remaining

\footnotetext{
${ }^{18}$ As discussed in Krusell et al. (2000) and Hornstein et al. (2005), these estimates cohere well with the microeconometric evidence reported in the literature.

${ }^{19}$ See also e.g. He and Liu (2008) for a similar approach.
} 
model parameters are common across these three cases, except for $\zeta$ and $\mu$ which are calibrated in each case to obtain the relative skill supply and skill premium in the data. ${ }^{20}$ Note that the steady-state solution for the model is the same for all three calibrations of $\psi$, given the re-calibration of $\zeta$ and $\mu$. Finally, note that the model's steady-state predictions for consumption and investment as a share of output of approximately 0.6 and 0.16 respectively, as well as the capital to output ratio of about 2 , are broadly in line with the stylised facts for the U.S. economy.

\subsection{Dynamic solution for 1970-2000}

Given the focus of our analysis, we next evaluate the ability of the model to capture the co-movement of the skill premium, the relative supply of skilled to unskilled workers and output. To achieve this, we solve and simulate the model using actual data for capital augmenting technology ${ }^{21}$ and the policy instruments for the period 1970-2000 and compare the model predictions to those in the actual data. ${ }^{22}$ Our simulations therefore include the main exogenous drivers of the skill premium considered in the literature, i.e. capital augmenting technology and policy. We solve all versions of our model, i.e. $(\psi=0,1,-1)$ as well as the case without social mobility.

To solve and simulate the model, we work as follows (see e.g. Conesa et al. (2007) and He (2012) for a similar approach). First, we solve the steadystate of the model for the tax and spending data in 1970, which implies that $\zeta$ and $\mu$ are calibrated in each case to obtain the relative skill supply and skill premium for 1970. The remaining parameters are as in Table 1 . We then solve the dynamic DCE system for $T$ periods, providing this system the time series for $B_{t}, \tau_{t}^{k}, \tau_{t}^{l}, g_{t}^{u}, g_{t}^{s}$ for the first 31 years and assuming that these exogenous variables remain flat at their 2000 value thereafter. Finally, we let $g_{t}^{c}$ be residually determined so that the government budget constraint is satisfied.

The initial conditions for the model's state variables are given by the 1970 solution. For the terminal values of the forward looking variables, we assume

\footnotetext{
${ }^{20}$ Note that this results in no differences in $\mu$ to three decimal places.

${ }^{21}$ To construct this measure, we follow $\mathrm{He}(2012)$ and use the quality-adjusted price index of total investment (in equipment and structures) and the official NIPA price index of consumption (nondurable and services) from Cummins and Violante (2002). The resulting capital augmenting technology index is then re-intialised to unity in 1970.

${ }^{22}$ Note that since we cannot disaggregate education spending data to pre-postgraduate and postgraduate education, we assume that government spending on skilled human capital moves proportionately to total government education spending. The degree of proportionality is, as discussed previously, equal to 0.1 .
} 
that after $T$ years the dynamic system has converged to its new steadystate. This implies that the appropriate terminal conditions are obtained by setting the values for these variables equal to those of the preceding period. After appropriate substitutions at the level of the DCE, the final system is given by $(8 \times T)$ equations, which is solved non-linearly using standard numeric methods (see, e.g. Garcia-Milà et al. (2010) and Angelopoulos et al. (2013b)). This gives the dynamic transition to the new steady-state for the model's endogenous variables. We set $T=400$ to ensure that convergence is achieved. Our results show that this occurs for all endogenous variables within 150 years.

Table 2: Model(s) vs data correlations

\begin{tabular}{lccc}
\hline \hline & $\rho\left(\frac{w^{s}}{w^{u}}, y\right)$ & $\rho\left(\frac{n^{s}}{n^{u}}, y\right)$ & $\rho\left(\frac{w^{s}}{w^{u}}, \frac{n^{s}}{n^{u}}\right)$ \\
\hline Data (1970-2000) & 0.928 & 0.970 & 0.849 \\
Model 1: $\psi=0$ & 0.965 & 0.972 & 0.921 \\
Model 2: $\psi=1$ & 0.980 & 0.978 & 0.982 \\
Model 3: $\psi=-1$ & 0.940 & 0.964 & 0.857 \\
Model 4: no soc. mob. & 0.981 & 0.000 & 0.000 \\
\hline
\end{tabular}

With the exception of the model without social mobility (i.e. Model 4), Table 2 suggests that Models 1-3 match the data correlations reasonably well. On balance, the model with positive externalities $(\psi=-1)$, appears to match the data correlations better than Models 1-2. All models slightly over-predict $\rho\left(\frac{w^{s}}{w^{u}}, y\right)$ with Model 3 showing a correlation which is closest to that in the data. While there is not much difference across models for $\rho\left(\frac{n^{s}}{n^{u}}, y\right)$ (except for Model 4), the correlation for Model 1 is the closest to the data correlation followed by Models 3 and 2 respectively. Finally Model 3 clearly outperforms all other models with respect to $\rho\left(\frac{w^{s}}{w^{u}}, \frac{n^{s}}{n^{u}}\right)$.

\section{Policy reforms}

In what follows, we first outline how we implement permanent policy reforms. We then turn to the analysis of the transition dynamics and long-run implications of the reforms. We focus on policies targeted at increasing physical capital via a capital tax cut and at encouraging skilled and unskilled human capital accumulation via increases in government spending of each education type. Policy reforms are financed by changes in the labor tax rate. 


\subsection{Implementation of reforms}

First, we solve for the pre-reform steady-state and assume that the economy has been in this equilibrium until period zero. Then, we impose the policy reform on the pre-reform equilibrium in period zero and obtain the dynamic solution of the non-linear system as discussed above. In particular, we impose the reform in period-0 and solve the dynamic DCE system for $T$ periods. We implement this by changing one policy instrument at a time and keeping it flat at its new post-reform value, while letting $\tau_{t}^{l}$ be residually determined to satisfy the government budget constraint. The remaining policy instruments are held fixed at their pre-reform values. The initial conditions for the model's state variables are given by the steady-state solution of the pre-reform economy. Terminal values of the forward looking variables and convergence are determined using the same procedure as described above. Our results again show that convergence occurs for all endogenous variables within 150 years.

In Figures 1-3, we plot the transition paths of the key endogenous variables of the system $\left\{c_{t}, y_{t}, k_{t+1}, l_{t}^{s}, l_{t}^{u}, h_{t+1}^{s}, h_{t+1}^{u}, n_{t+1}^{s}, \frac{w^{s}}{w^{u}}, \tau_{t}^{l}\right\}_{t=0}^{T^{*}}, T^{*}=150$ for each reform considered. In each Figure, we plot the paths for all versions of our model, i.e. $(\psi=0,1,-1)$ as well as the case without social mobility.

\subsection{Tax reform: a capital tax cut}

We first examine the case of a revenue neutral, elimination of the capital tax in Figure 1. Consistent with the literature (see e.g. Mankiw et al. (2009), Garcia-Milà et al. (2010) and Ljungvist and Sargent (2012) for reviews), a capital tax cut is expected to improve aggregate outcomes in representative agent models, especially over longer time horizons. Figure 1 shows that output increases post-reform, while consumption increases after the initial 1020 years, since in the initial post-reform years the household finds it optimal to increase investment and reduce consumption, in response to the higher returns to physical capital.

[Figure 1 here]

As the plot for the skill premium suggests, this improvement in aggregate outcomes also implies increased wage inequality. The reason is that the policy-induced increase in the capital stock is skill-biased because capital complements skilled labour more than unskilled. Hence, as discussed in subsection 2.7, the skill premium increases with the capital stock post-reform. These effects are qualitatively similar across the four versions of the model. However, the models that allow for endogenous accumulation of skill, also 
predict that social mobility will increase post-reform, as can be seen in the plot for the skilled share in the population. As pointed out in sub-section 2.7, an increase in the skill premium works to encourage the accumulation of unskilled human capital, as a means to increase social mobility to capture the higher returns associated with skilled employment. ${ }^{23}$ In turn, this has important quantitative effects on the skill premium, as the resulting increase in the relative skill supply acts to lower the skill premium. ${ }^{24}$ In fact, the reduction in the skill premium starts taking effect 20-30 years after the reform, when the increase in the share of skilled labour is sufficiently strong to counterbalance the increase in the capital stock. As a result, the dynamic response of the skill premium is hump-shaped and suggests that it over-shoots in the short- to medium-run compared with its long-run value. Nevertheless, the relative supply effects are not strong enough to dominate the skill-biased increase in the capital stock in the long-run, so that the skill premium is higher post-reform.

Our analysis suggests that there are important quantitative differences between models that allow for social mobility, regarding their predictions for the effects of a capital tax cut. In particular, the wage inequality effects are dampened. At the same time, the aggregate output and consumption effects are higher, since the economy benefits from the increase in the share of skilled workers whose productivity is higher. We conclude, therefore, that excluding social mobility from models with capital-skill complementarity leads to under-predicting the positive effects of capital tax cuts, by under- and overestimating, respectively, the aggregate efficiency and wage inequality effects. We also see in Figure 1 that the existence of either positive or negative externalities from skilled human capital in the social mobility function is not important for this result, since the model predictions are similar quantitatively for both versions of the model, especially in the medium- to long-run. This is due to the fact that skilled human capital, while changing in the short-run, reverts to its pre-reform steady-state by the medium-run.

\footnotetext{
${ }^{23}$ Recall that an increased quantity of human capital for the unskilled workers, has two effects on the relative skill supply. On one hand, it increases the effective labour supply of unskilled labour, and thus tends, ceteris paribus, to decrease the effective relative skill supply. However, at the same time, by increasing the proportion of skilled members, through the social mobility function, it tends to increase the effective relative supply of skilled labour. The second effect dominates here given the large increase in social mobility.

${ }^{24}$ Our results are generally consistent with $\mathrm{He}$ and Liu (2008), who also find that in a calibrated model with endogenous skill accumulation, capital tax cuts will increase the skill premium, while, at the same time, increasing the relative skill supply.
} 


\subsection{Increases in $g^{u}$}

We next examine the effects of a $50 \%$ increase in government spending on education that aims to encourage the accumulation of human capital for unskilled workers. The post-reform dynamic paths are plotted in Figure 2. As expected, the stock of human capital for unskilled labour increases and this raises output in all models and social mobility in the models that allow for endogenous skill accumulation. In turn, as discussed in sub-section 2.7, this increase in the relative supply of skill leads to a decline in the skill premium in the medium- to long-run. However, initially, the skill premium increases. This is because the labour productivity gains, brought about by the increase in human capital, also increase the return to physical capital and thus lead to increased capital stock, which tends to increase the skill premium. When the relative skill supply has increased sufficiently, the skill premium starts to decline. In this case, in fact, the increase in the share of skilled in the population is sufficiently strong to decrease the skill premium in the longrun. Therefore, the dynamic processes of human capital accumulation and social mobility have non-trivial implications on the joint determination of the paths for skill premium-social mobility. In particular, although wage inequality is reduced in the long-run, along with increased social mobility, this implies increased wage inequality in the short- to medium-run (about 10 years post-reform), as can be seen by the hump-shaped reaction of the skill premium.

\section{[Figure 2 here]}

In the long-run, government spending on unskilled education, by increasing the labour productivity of unskilled labour and increasing their skill accumulation, raises output, reduces wage inequality and improves social mobility. Note, however, that consumption is reduced, due to the increase in the distortionary labour tax required to finance the higher education spending, which implies that the output gains are not big enough to accommodate the increase in investment in physical capital and government education spending as well. As a result, the increase in government education spending crowds out private consumption.

The effects of the increase in $g^{u}$ are effectively identical for all versions of the model that assume $\psi=0,1,-1$ for the same reasons as explained above. However, the plots in Figure 2 again suggest that there are important differences between these three versions of the model and the model without social mobility. The absence of the latter implies that the skill premium post-reform will increase, as the rise in the human capital of the unskilled increases the relative supply of skilled in labour efficiency units, while the increase in the capital stock also favours skilled labour. Thus, both factors 
tend to increase wage inequality. Moreover, the effects of the policy reform on aggregate output and consumption are worse in this model. Therefore, as in the previous case, ignoring social mobility results in underestimating the effects of government education spending on output and consumption and in overestimating the effects on wage inequality.

\subsection{Increases in $g^{s}$}

We next examine the effects of a $50 \%$ increase in government spending on education that aims to encourage the accumulation of human capital for skilled workers. The post-reform dynamic paths are plotted in Figure 3. In principle, this should not be expected to directly affect social mobility, at least when $\psi=0$, so we start our analysis from this case. An increase in public funding for skilled human capital increases the quantity of skilled human capital and thus the effective supply of skilled labour. This in turn acts to lower the skill premium (see the discussion in sub-section 2.7), despite the increase in physical capital. These movements are confirmed in Figure 3.

\section{[Figure 3 here]}

The fall in the skill premium tends, other things equal, to decrease the incentives to become skilled for the reasons outlined in sub-section 2.7. However, the increase in the relative quantity of skilled human capital, increases future productivity differentials, as captured by the difference between skilled and unskilled human capital, and thus acts to support the desire for employment in the skilled sector (see equation (18)). As a result, social mobility increases. Moreover, the increased productivity in the economy increases output and consumption. Therefore, compared with public spending on the education of the unskilled and capital-tax induced physical capital supporting policies, increases in public spending on the productivity of skilled labour appear to be able to increase aggregate output and consumption while decreasing social and wage inequality as well.

However, in contrast to our finding thus far, these results are sensitive to the assumption of the externalities that skilled human capital may have on social mobility. When these externalities are negative (i.e. when $\psi=1$ ), the effects of social mobility and wage inequality are reversed, while the positive aggregate effects on output and consumption are reduced. The reason is that the increase in the human capital of the skilled members now makes it more difficult for unskilled members to become skilled, thus reducing social mobility. In turn, this decreases the relative supply of skilled labour, such that the skill premium increases. In contrast when externalities are positive (i.e. 
when $\psi=-1$ ), the beneficial effects on social mobility, wage inequality, and welfare are enhanced relative to the $\psi=0$ case. This is because higher levels of skilled human capital increase the productivity of individual investment in school level and college education.

Finally, the model with a fixed share of skilled workers in the labour force underestimates the positive aggregate effects on output and consumption and the decline in the skill premium, compared with the $\psi=0,1-1$ models, since it misses the positive effects of the reform on social mobility. ${ }^{25}$

\section{Conclusions}

This paper examined the role of human capital and economic policy in the joint determination of the skill premium and the transition from unskilled to skilled employment. To achieve this, we developed a DGE model with human capital incorporating capital-skill complementarity and endogenous social mobility. We found that incorporating endogenous versus fixed social mobility allowed us to capture the empirical co-movement of the skill premium, the relative supply of skilled to unskilled workers and aggregate output in the U.S. data from 1970-2000. The model predictions are closer to the empirical co-movements when we allow for positive externalities from skilled human capital on social mobility.

Our setup first implied that the wage inequality effects of capital tax cuts are significantly dampened by the increase in the relative skill supply, which follows the increased returns to upward social mobility, while, at the same time, the aggregate efficiency effects of the capital tax cut become stronger. Thus, excluding endogenous social mobility from models with capital-skill complementarity underestimates the beneficial effects of capital tax cuts by under-predicting the positive output and consumption effects and over-predicting the negative wage inequality effects.

Second, we found that the qualitative effects of public spending education policies on the skill premium change with endogenous social mobility. In particular, it is only when we account for social mobility that an increase in education spending for the unskilled lowers the skill premium, while simultaneously increasing the relative skill supply. Thus, as with capital tax cuts, ignoring social mobility results in an under- and over-estimation, respectively, of the aggregate efficiency and wage inequality effects of government education spending for unskilled labour.

\footnotetext{
${ }^{25}$ Note that effects of public education spending discussed in the last two sub-sections are qualitatively robust to changes in the education productivity parameter, $\gamma$, consistent with our base calibration.
} 
Third, our analysis suggested that, in the absence of externalities, increases in government spending on the education of the skilled agents has positive effects on output and consumption, as well as encouraging social mobility, despite the reduction in the skill premium. This occurs because, by supporting the productivity of the skilled, the government indirectly increases the potential future benefits of the unskilled, if they succeed in climbing the social ladder. These positive outcomes are again under-estimated when the effects of this type of policy on social mobility are ignored. However, these results are sensitive to whether externalities of skilled human capital on social mobility are positive or negative. The former enhance the positive effects on social mobility, wage inequality, and welfare, whereas the latter reverse them for social mobility and wage inequality and lower them for welfare.

\section{References}

[1] Acemoglu, D. and D. Autor (2011). 'Skills, tasks and technologies: implications for employment and earnings', in O. Ashenfelter and D. Card (eds.), Handbook of Labor Economics, 4b, 1043-1171, Amsterdam: Elsevier.

[2] Angelopoulos, K., Fernandez, B., and J. Malley (2013a). 'The distributional consequences of tax reforms under capital-skill complementarity, Economica, forthcoming.

[3] Angelopoulos, K., Jiang, W. and J. Malley (2013b). 'Tax reforms under market distortions in product and labour markets', European Economic Review, 61, 28-42.

[4] Ardagna, S. (2007). 'Fiscal policy in unionized labor markets', Journal of Economic Dynamics and Control', 31, 1498-1534.

[5] Arseneau, D. and S. Chugh (2012): 'Tax smoothing in frictional labor markets', Journal of Political Economy, 120, 926-985.

[6] Autor, D., Katz, L. and M. Kearney (2008). 'Trends in U.S. wage inequality: revising the revisionists', The Review of Economics and Statistics, 90, 300-323.

[7] Bénabou, R. and E., Ok (2001). 'Social mobility and the demand for redistribution: the Poum hypothesis', The Quarterly Journal of Economics, 116, 447-487. 
[8] Card, D. and T. Lemieux (2001). 'Going to College to Avoid the Draft: The Unintended Legacy of the Vietnam War', American Economic Review, 91, 97-102.

[9] Card, D. and J. Di Nardo (2002). 'Skill-biased technological change and rising wage inequality: some problems and puzzles', Journal of Labor Economics, 20, 733-783.

[10] Conesa, J.C., Kehoe, T. and K. Ruhl (2007). 'Modeling Great Depressions: The Depression in Finland in the 1990s', Quarterly Review, Federal Reserve Bank of Minneapolis, Nov, 16-44.

[11] Cozzi, G. and G. Impullitti (2010). 'Government spending composition, technical change, and wage inequality', Journal of European Economic Association, 8, 1325-1358.

[12] Cummins, J. and G. Violante (2002). 'Investment-specific technical change in the US (1947-2000): measurement and macroeconomic consequences', Review of Economic Dynamics, 5, 243-284.

[13] Cúrdia, V. and M. Woodford (2009). 'Credit frictions and optimal monetary policy', BIS Working Papers 278, Bank for International Settlements.

[14] Eicher, T. and C. Garcia-Penalosa (2001). 'Inequality and growth: the dual role of human capital in development', Journal of Development Economics, 66, 173-197.

[15] Galor, O., Moav, O. and D. Vollrath (2009). 'Inequality in land ownership, the emergence of human-capital promoting institutions, and the great divergence', Review of Economic Studies, 76, 143-179.

[16] Galor, O. and O. Moav (2006). 'Das human-kapital: A theory of the demise of the class structure', Review of Economic Studies, 73, 85-117.

[17] Galor, O. and O. Moav (2000). 'Ability-biased technological transition, wage inequality, and economic growth', The Quarterly Journal of Economics, 115, 469-497.

[18] Garcia-Milà, T., Marcet, A. and E. Ventura (2010). 'Supply side interventions and redistribution', Economic Journal, 120, 105-130.

[19] He, H. (2012). 'What drives the skill premium: technological change or demographic variation?' European Economic Review, 56, 1546-1572. 
[20] He, H. and Liu, Z. (2008). 'Investment-specific technological change, skill accumulation, and wage inequality', Review of Economic Dynamics, 11, 314-334.

[21] Heckman, J., Lochner, L. and C. Taber (1998). 'Tax Policy and HumanCapital Formation', American Economic Review, 88, 293-297.

[22] Hornstein, A., Krusell, P. and Violante, G. (2005). 'The effects of technical change on labor market inequalities', in P. Aghion and S. Durlauf (eds.), Handbook of Economic Growth, vol. 1, 1275-1370. Amsterdam: Elsevier.

[23] Katz, L. and K. Murphy (1992). 'Changes in relative wages, 1963-1987: supply and demand factors', The Quarterly Journal of Economics,107, $35-78$.

[24] Krusell, P., Ohanian, L., Ríos-Rull J. and Violante, G. (2000). 'Capitalskill complementarity and inequality: a macroeconomic analysis', Econometrica, 68, 1029-1053.

[25] Lucas, R. (1988). 'On the mechanics of economic development', Journal of Monetary Economics, 22, 3-42.

[26] Ljungvist, L. and Sargent, T. (2012). Recursive Macroeconomic Theory, 3rd Edition, The MIT Press.

[27] Maoz, D. and O. Moav (2004). 'Social stratification, capital skill complementarity, and the non-monotonic evolution of the education premium', Macroeconomic Dynamics, 8, 295-309.

[28] Mankiw, G., Weinzierl, M. and D. Yagan (2009). 'Optimal taxation in theory and practice', Journal of Economic Perspectives, 23, 147-174.

[29] Matsuyama K. (2006). 'The 2005 Lawrence R. Klein Lecture: emergent class structure', International Economic Review, 47, 327-360.

[30] Garcia-Penalosa, C. and K. Wälde (2000). 'Efficiency and equity effects of subsidies to higher education', Oxford Economic Papers, 52, 702-722.

[31] Perli, R. and P. Sakellaris (1998). 'Human capital formation and business cycle persistence', Journal of Monetary Economics, 42, 67-92.

[32] Piketty, T. (1995). 'Social mobility and redistributive politics', The Quarterly Journal of Economics, 110, 551-584. 
[33] Pissarides, C. (1998). 'The impact of employment tax cuts on unemployment and wages: the role of unemployment benefits and tax structure', European Economic Review, 42, 155-183.

[34] Rogerson, R. and R. Shimer (2011): 'Search in macroeconomic models of the labor market', in Handbook of Labor Economics, vol. 2, edited by O.Ashenfelter, R. Layard, and D. Card, Amsterdam: Elsevier.

[35] Tamura R. (1991). 'Income convergence in an endogenous growth model', Journal of Political Economy, 99, 522-540.

\section{Appendix: Uniqueness of solution}

\subsection{Analytic results}

A unique equilibrium requires that the primitive functions describing preferences and technology, as well as the constraints, are at least quasi-concave. With the exception of the constraint referring to the share of skilled members, it is well known that the remaining functions in our model satisfy this condition. To check the skilled share defined on the positive quadrant $\mathbb{R}_{+}^{2}$ as:

$$
n_{t+1}^{s}=\frac{n_{t}^{s}+e^{\left(\frac{-\zeta S^{*}\left(\bar{h}_{t+1}^{s}\right)^{\psi}}{h_{t+1}^{u}}\right)}\left(1-n_{t}^{s}\right)}{1+\theta}
$$

we next sign the leading principle minors of the Hessian matrix, $D^{2} f(\mathbf{x})$, of (31), where $D$ is the matrix derivative operator and $\mathbf{x}=\left(\begin{array}{c}n_{t}^{s} \\ h_{t+1}^{u}\end{array}\right)$. The principle minors, given by:

$$
\begin{gathered}
\frac{\partial^{2}\left(n_{t+1}^{s}\right)}{\partial\left(n_{t}^{s}\right)^{2}}=0 \\
\left|D^{2} f(\mathbf{x})\right|=-\frac{\left[\zeta S^{*}\left(\bar{h}_{t+1}^{s}\right)^{\psi}\right]^{2} e^{\left(\frac{-2 \zeta S^{*}\left(\bar{h}_{t+1}^{s}\right)^{\psi}}{h_{t+1}^{u}}\right)}}{(1+\theta)^{2}\left(n_{t}^{s}\right)^{4}}<0,
\end{gathered}
$$

imply that the matrix $D^{2} f(\mathbf{x})$ is indefinite. Thus, (31) is neither concave nor convex on $\mathbb{R}_{+}^{2}$.

\subsection{Simulation results}

Since we cannot analytically establish uniqueness, we numerically check for potential multiple equilibria by solving the nonlinear dynamic system of 
$(8 \times T)$ for $T=400$ over a range of initial values for the models statevariables including $k_{t}, h_{t}^{s}, h_{t}^{u}$, and $n_{t}^{s}$. Conditional on the calibration discussed in Table 1, we construct this range such that initial values for each state-variable is up to $65 \%$ above and below their respective steady-state value.

In all cases, we find that dynamic transition paths for all endogenous variables revert to their unique steady-state equilibrium values. This finding also applies if we change the initial values of all the state-variables simultaneously by the same percentages. If we move beyond $\pm 65 \%$ change in initial values, we find that the model no longer solves which is not surprising given that changes of such magnitude are no longer consistent with the calibration.

Thus, we conclude that the equilibrium is uniquely defined for very large deviations of the economy's state variables from the steady-state. Moreover, by linearising around the unique steady-state and using standard eigenvalue tests, we also find that the equilibrium is locally stable. 
Figure 1: fall in $\tau^{k}$ to 0
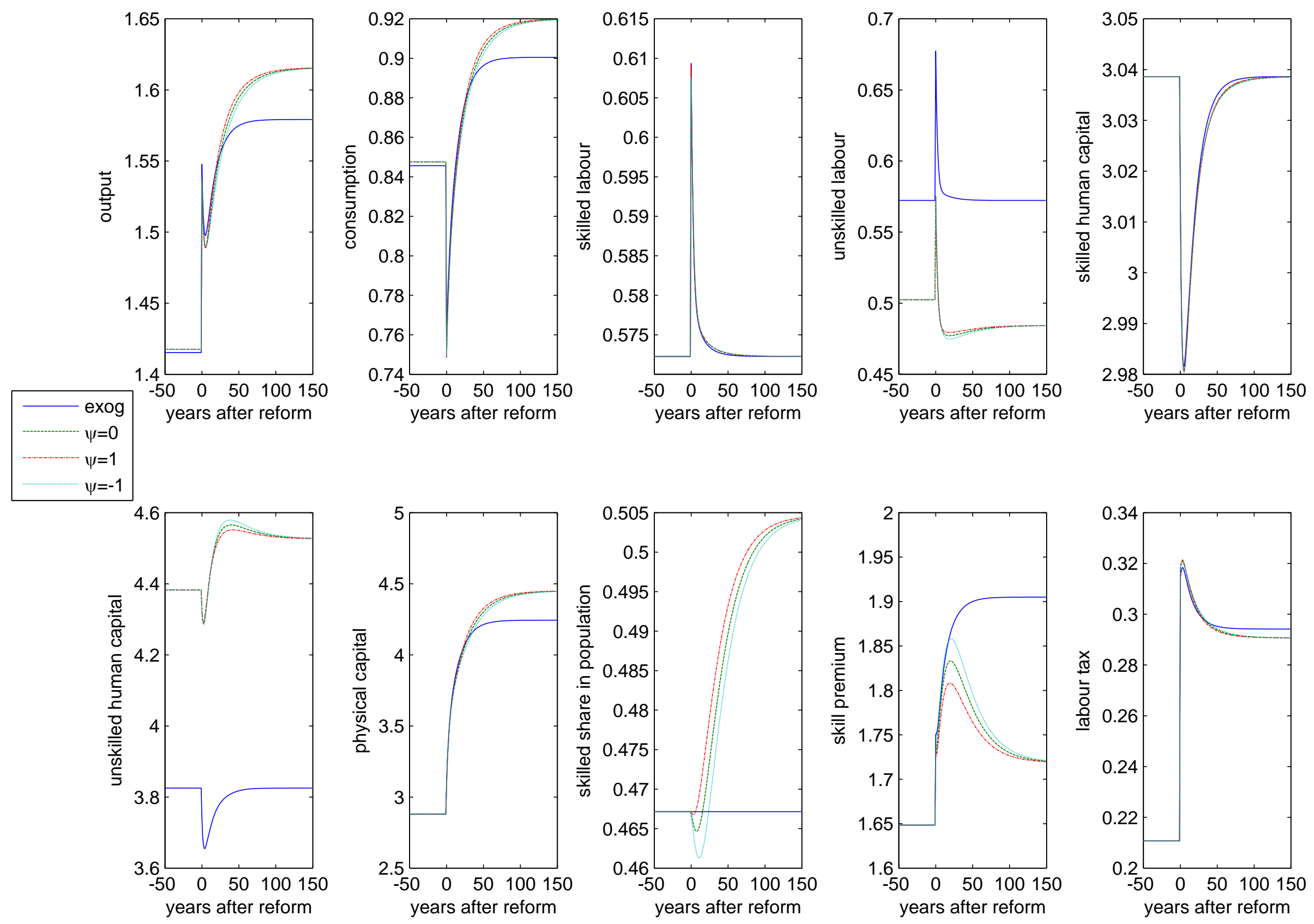
Figure 2: rise in $\mathrm{g}^{\mathrm{u}}$ by $50 \%$
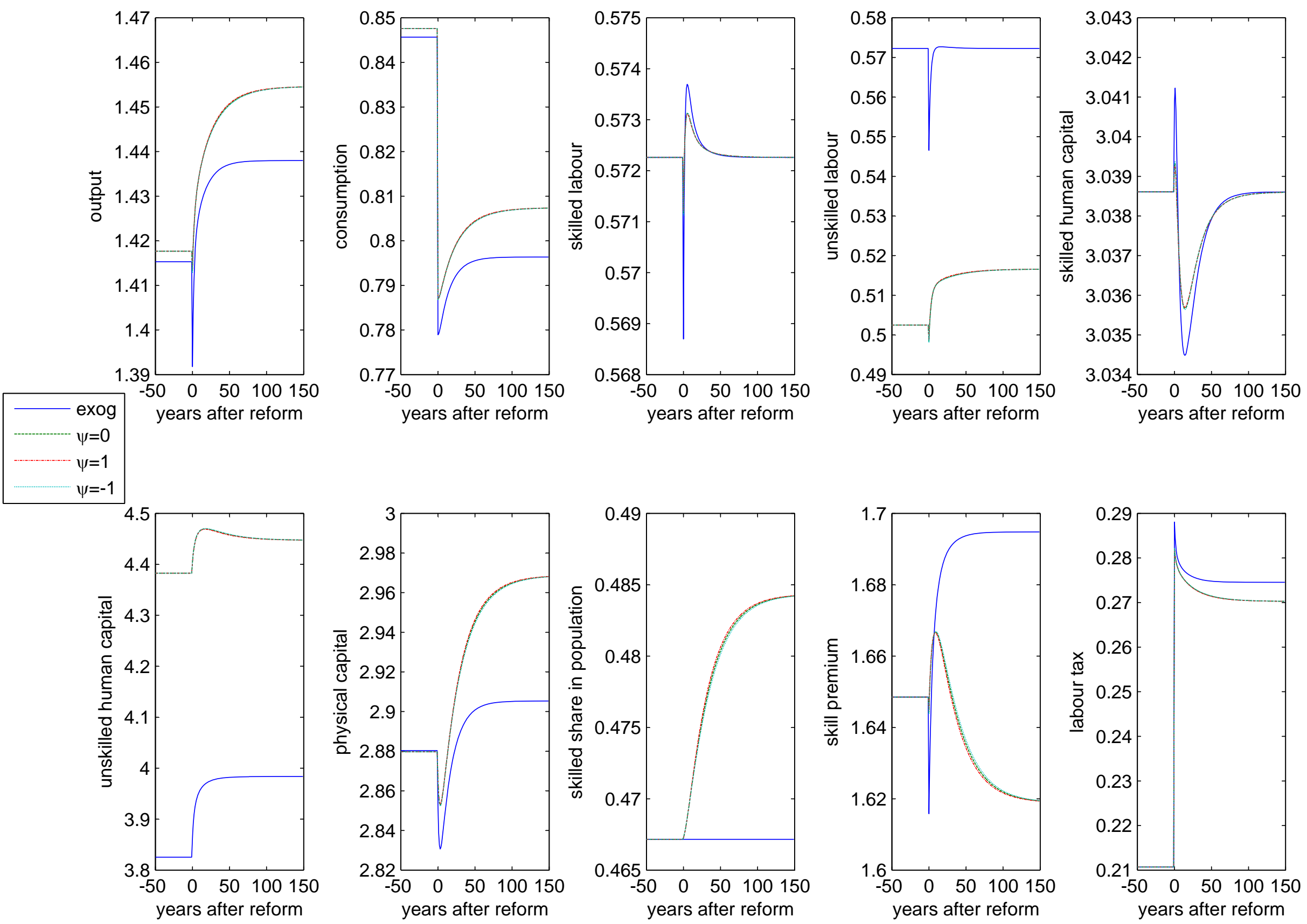
Figure 3: rise in $\mathrm{g}^{\mathrm{s}}$ by $50 \%$
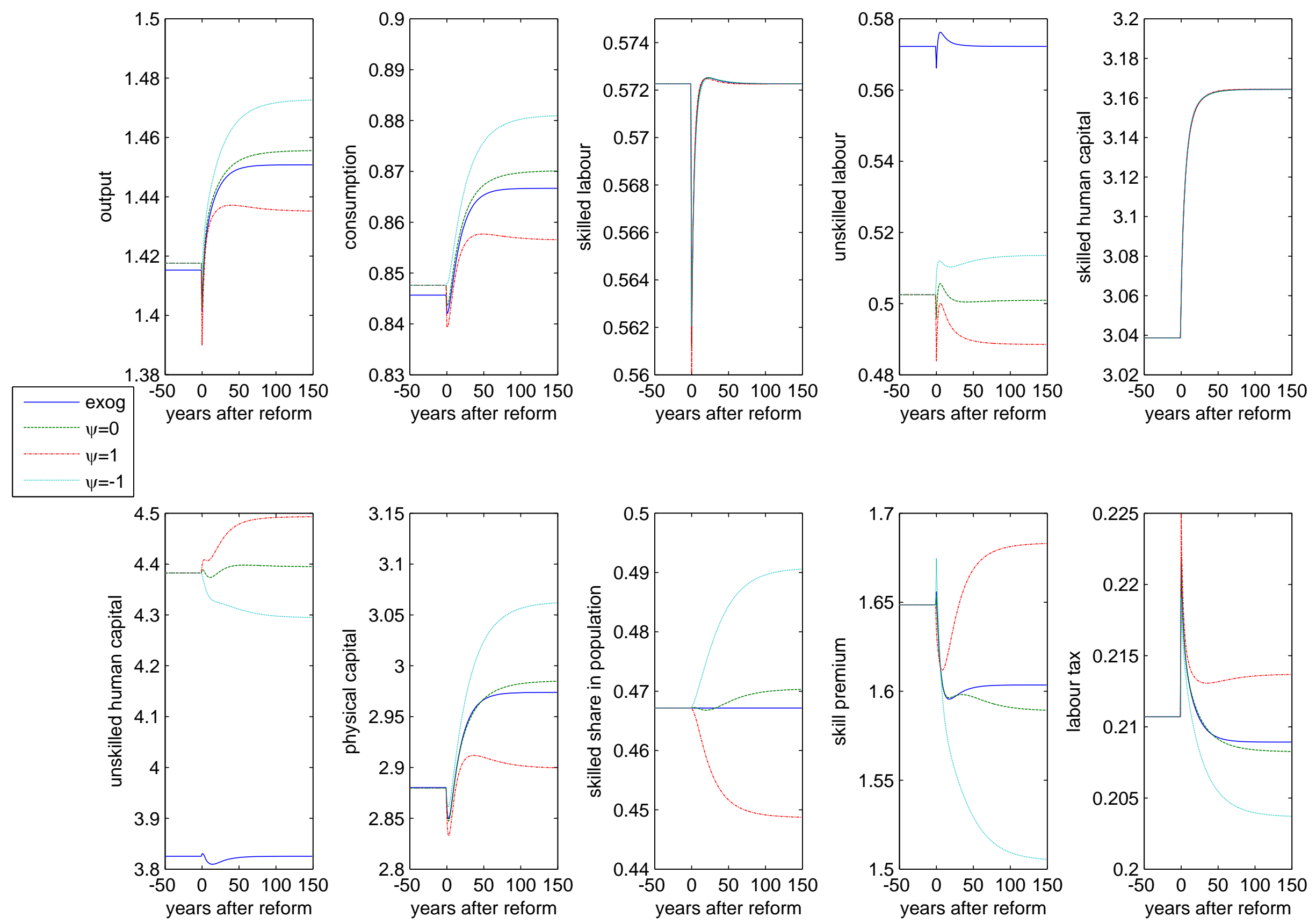